\title{
A Case of Pycnodysostosis
}

\author{
- Its Oral Aspects - \\ by \\ Hideaki FUKADA*, Susumu UEHARA* Shoichi ANDO**
and Koji SHINODA**
}

As the pedodontists rather frequently encounter cases of the congenital abnormalities or developmental anomalies in their daily practice, it is essential that they should possess an adequate knowledge of those anomalies in order to give proper diagnosis and establish effective treatment planning.

Recently, we have observed a case of pycnodysostosis in a ten-year-six-month old girl, whose dental characteristics provide some additional findings to those already pointed out by previous investigators in the field.

The pycnodysostosis was first defined by MAROTEAUX-LAMY [1] as an independent entity which differs from Albers-Schönberg disease in points of the anomaly of cranial, peripheral bone and the mandible. Since MAROTEAUX-LAMY first reported on this in 1962, other case reports were followed by SHULER [2] in 1963, STANESCO [ 3 ] in 1964, and Wiedemann [4] in 1965.

As the first effort by a domestic researcher, the one by MURAKAMI et al. [5] was the presentation of systemic findings on the same patient as reported in this paper.

\section{Case History}

Chief complaint: The patient, 10-year-6-month old girl, visited the pedodontic clinic at Nihon University School of Dentistry, seeking the diagnosis and treatment for the malposed tooth alignment.

Past medical history: At the birth, biologic data of the patient were $2,510 \mathrm{gm}$ in weight, $48 \mathrm{~cm}$ in height, cranial circumferance $32.5 \mathrm{~cm}$ and the chest was $31 \mathrm{~cm}$. Neck control developed at the age of 4 months, walking began at 12 months. The developmental levels of personality and motor function showed no significant differrence though the entire physical build-up gave evidence of the abnormality. Physical growth has been much retarded and it began to be noticed since the preschool period. At the time of her entrance to elementary school, she measured only $95 \mathrm{~cm}$ in height.

In health condition, none of specific disease experiences was reported, except measles at the age of two, and chicken pox at the age of ten.

Family history: Consanguinity in marriage is denied by the parents. The mother's height is fairly short in $119 \mathrm{~cm}$; however, none of specific findings revealed itself under roentgenological examination of the bone. There are 7 siblings on the maternal side, none of whom give any suspicion of an abnormal problem. It is, however, to be noted that the features of grand-mother on the maternal side bear a high degree of

* 深田 英朗, 上原 進: Dept. of Pedodontics, Nihon Univ. School of Dentistry.

** 安藤 IE一, 篠田 宏司: Dept. of Radiology, Nihon Univ. School of Dentistry. 
resemblance to those of the patient. There are 6 siblings on the paternal side; all of them are short in stature but in normal healthy condition otherwise.

\section{Characteristic findings in general condition:}

Physical growth of the patient at the time of our examination gave these data : $103 \mathrm{~cm}$ in height, $17 \mathrm{~kg}$ in weight $49 \mathrm{~cm}$ in cranial circumferance and $53 \mathrm{~cm}$ in chest, $60 \mathrm{~cm}$ in sitting height. As compared with an average child of her age, she is quite short and this is even so in contrast brother aged six, as shown in Fig. 1. The hands and feet had remarkably stub fingers and toes. Hypoplastic nails are obvious on the first, second, third fingers of the right and on the first and second fingers of the left hand (Fig. 2).

In roentgenograms, there have been recognized the delicately formed midsegments of the finger bone in both the hands and feet. Also, the hyperossified feature is observable in long bone. (Fig. 3).

Characteristics of cranio-facial and dental aspects.

Facial expression of the patient is somewhat obvious in a shape, i. e., expanded frontal region, poor development of the mandible, Fonticulus major and minor are left open, and the cranial sutures are not

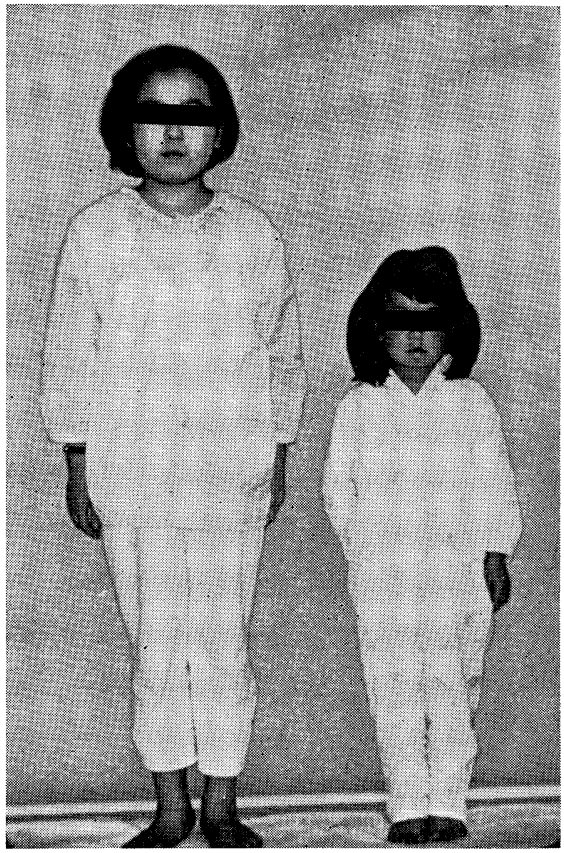

Fig. 1.

Right : Pycnodysostosis child, notice short height.

Left : Normal child, average height of the same age girl.

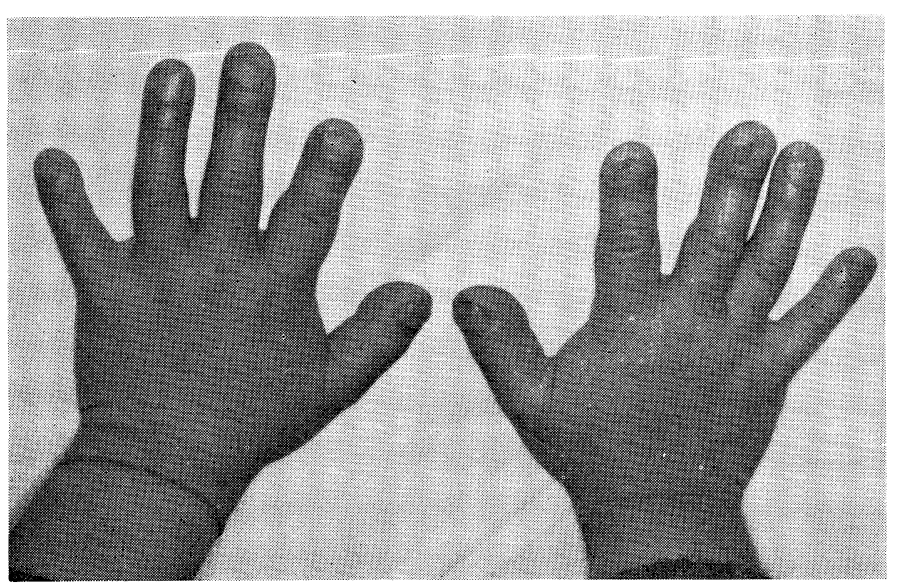

Fig. 2.

Notice short thick fingers and the dark discoloration of the nails which poorly keratinized. 


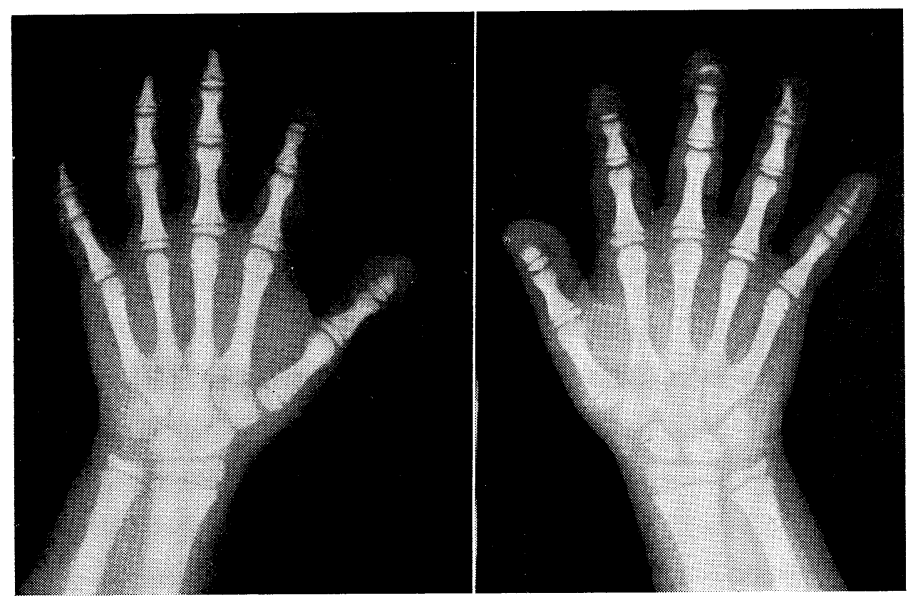

Fig. 3.

Radiograph of the hands.

closed yet, although any sign of hypercephalitis is not recognized.

In her dental aspects, the teeth are malposed and the arch contains congenitally missing teeth. The gingiva shows normal healthy color, but the tension of the gingival tissue is loose to the touch. Gingival pockets are fairly deep in the anterior region. The palate which has the shape of a letter $\mathrm{V}$ is generally and shallow (Fig. $6-\mathrm{a}, \mathrm{b})$.

Ossified features of the cranial base, opening of the sutures and hypoplastic character of the processus dorsi sellae were recognized in X-ray examination. The development of facial bone and the mandible is generally retarded, and, in particular, the ramus of the mandible is very thin with an obtuse angle. The shadow of the frontal sinus is quite obscure (Fig. 5).

The crest line of alveolar bone at the upper first bicuspid to the first molar on both sides, has been absorbed in such a manner that its root height is just half of the normal one and this gives the impression that it is extremely absorbed level buccopalatally.

Periodontal space at the distal root of the right upper first bicuspid is enlarged, and the bone matrix became loose to the area of first molar on the same side.

In anterior region, horizontal absorption and destruction of the lamina dura has advanced to the level of half of the root observed on upper jaw. The same behavior of the absorption is seen in lower anterior region up to the level of half of the root.

Growth and developmental characteristics by Downs analysis failed to bring forth a satisfactory analysis. It, however, showed pronounced deviations from the standard data in faical angle and mandibular plane angle, indicative of the abnormally retarded development of the facial and mandible bone. Particular attention is drawn to an abnormal projection of the mandible angle in skeletal pattern.

In dental pattern, the score of L-1 to occlusal, U-1 to A-P plane are in less valued than the average, which can be also interpreted as resulting from retarded development of the midfacial portion and the mandibular surface. 


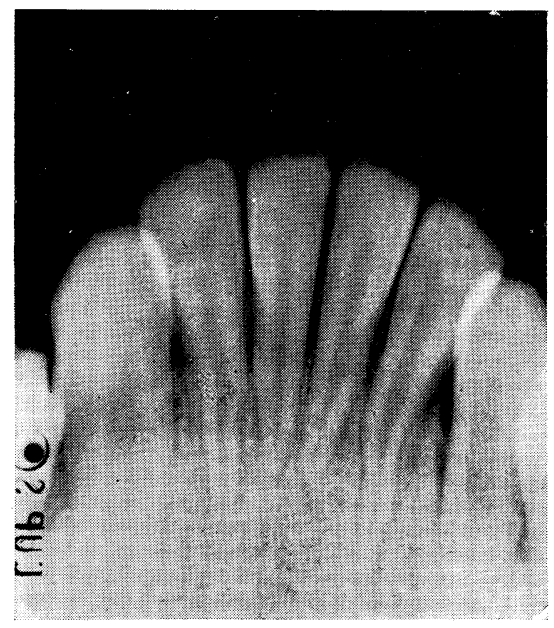

Fig. 4.

Notice the excess bone loss which indicates the sign of periodontosis like feature.

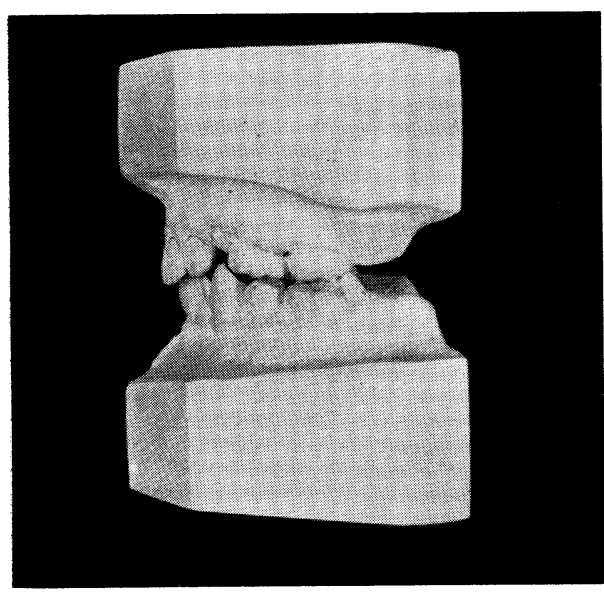

Fig. 6-a.

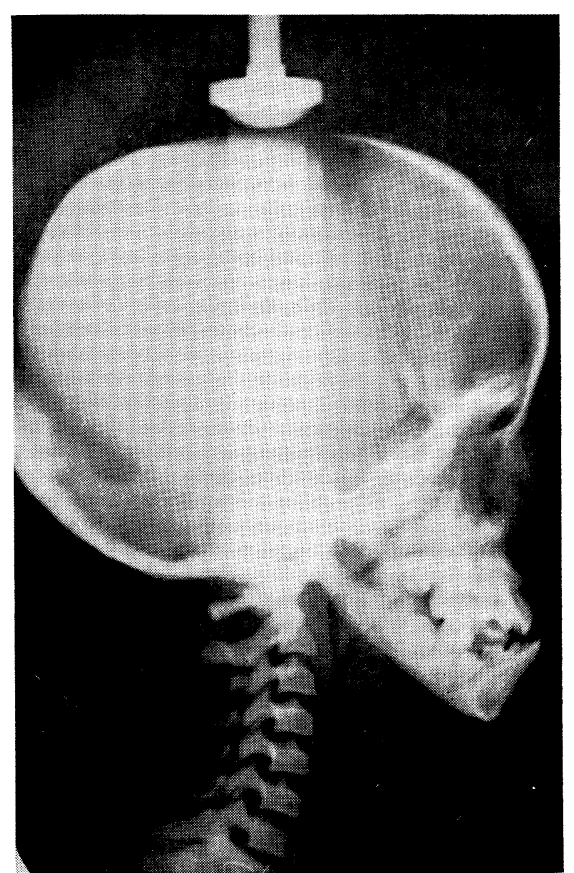

Fig. 5.

Cephalogram: Notice parietomastoid, coronal, lambdoidal sutures are remained open.

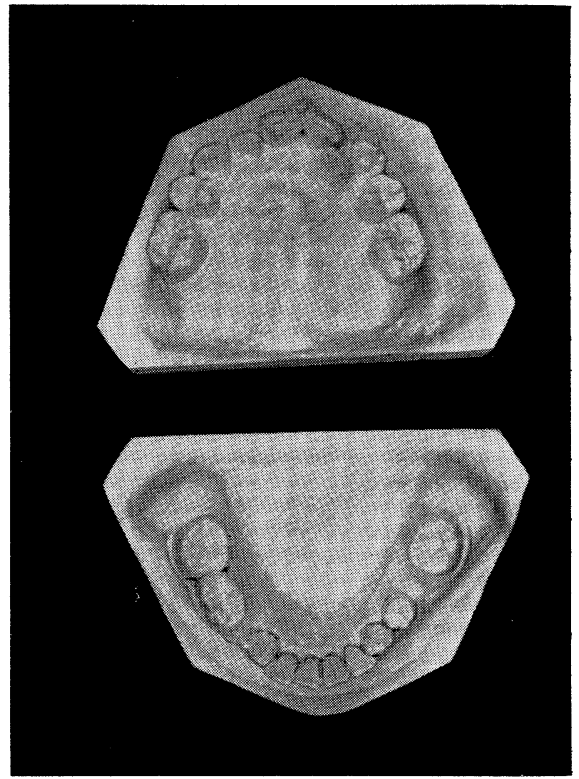

Fig. 6-b.

Study models showing malposed teeth, missing, and malocclusion. 


\section{Discussion}

Since the detailed report dealing with overall picture of the present case was already made public [5], our discussion here is limited only its dental findings.

The characteristics of the pycnodysostosis are found in the expansion of the frontal and occipital bone, retarded mandible, association of the anomalies with the palate, abnormal tooth number, and dental alignment. These characteristics are also the findings seen in the cases of cleido-cranial dysostosis and other cranio-facial dysostosis. From this point of view, RUBIN [6] defined the pycnodysostosis as a subgroup of the cleido-cranial dysostosis.

The diagnosis of the present patient as pycnodysostosis has been established by a joint opinion of our staff both in the schools of medicine and dentistry, by whose hand examination of the systemic conditions and other characteristics was conducted.

This case is full of interest from a dental point of view, as it is associated with periodontosis. The definite etiological factor is not evaluated at the moment, but we are inclined to think that periodontosis will appear as part of syndrome of this complaint.

This is endorsed by the fact that COHEN [6] and FUKADA [7] explain the primary cause of the periodontosis as derived from the metabolic disturbance and secretory dysfunction.

TABLE 1

Comparison of the Dental Characteristics with Cleido-cranial Dysostosis and Pycnodysostosis

\begin{tabular}{|c|c|c|c|c|c|}
\hline Findings & KINOSHITA $^{9)}$ & FUKUHARA $^{10)}$ & OCHIAI $^{11)}$ & KISHIMOTO ${ }^{12)}$ & $\begin{array}{l}\text { FUKADA } \\
\text { Pycno- } \\
\text { dysostosis }\end{array}$ \\
\hline $\begin{array}{l}\text { Retarded eruption } \\
\text { of the permanent } \\
\text { ant. teeth }\end{array}$ & + & + & + & + & - \\
\hline Delayed exfoliation & + & + & + & + & - \\
\hline Malocclusion & Class III & III & 0 & $\stackrel{+}{\text { Class III }}$ & $\begin{array}{l}+\dot{+} \\
\text { I } \\
\text { III }\end{array}$ \\
\hline $\begin{array}{l}\text { Abnormal crown } \\
\text { shape }\end{array}$ & - & - & - & - & - \\
\hline $\begin{array}{l}\text { Supernumerary } \\
\text { tooth }\end{array}$ & + & - & + & - & - \\
\hline Missing tooth & + & + & + & - & - \\
\hline $\begin{array}{l}\text { Retarded growth } \\
\text { of the maxilla }\end{array}$ & + & + & + & $\begin{array}{l}\text { may have } \\
\text { slight } \\
\text { retardation }\end{array}$ & $\begin{array}{c}+ \\
\text { severe } \\
\text { retardation }\end{array}$ \\
\hline $\begin{array}{l}\text { Hypoplasia of the } \\
\text { mandible }\end{array}$ & Mand. & $\begin{array}{l}{ }_{\text {Mand. angle }}^{+} \\
\text {abn. }\end{array}$ & - & $\begin{array}{c}\text { Mand. angle }_{\text {abn. }}^{+} \\
\text {a }\end{array}$ & $\begin{array}{c}{ }^{+} \\
\text {Mand. angle } \\
\text { lost ramus } \\
\text { hypo. }\end{array}$ \\
\hline Periodontosis & - & - & - & - & + \\
\hline Abnormal palate & - & - & - & - & + \\
\hline
\end{tabular}


The poorly mineralized frontal, parietal and occipital bones at their margins creating an appearance of wide sutures are observed in Hallermann-Streiff syndrome and other dysplasia [13].

Present case of pycnodysostosis also showed the characteristics obviously seen in the above mentioned syndrome.

The Table 1 shows the findings on dysostosis cleido-cranialis and the pycnodysostosis in domestic publications.

\section{References}

[1] Maroteaux, P. et Lamy, M. : Deux observations d'une affection osseuse condensantes : La pycnodysostose, Arch. franç. Pediat., 19 : 267, 1962 a.

[2] Shuler, S. : Pycnodysostosis. : Arch, dis. Child., 38 : 620, 1963.

[3] Stanesco, V., et al. : Une nouvelle observation de pycnodysostose avec étude metabolique, Arch. franç. Pediat., 21 : 135, 1964.

[4] Wiedemann, H. R. : Pyknodysostose, Fortschr. Röntgenstr., 103 : 5, 1965.

[5] Muraki, E., Noro, S., Sawaki, H., Okubo, N. and Uehara, S. : On the Pycnodysostosis, Acta pediatrica japonica, : 71: 3., 250, 1967.

[6] Rubin, P.: Dynamic classification of bone dysplasis, 1960.

[ 7] Cohen, M. A., Winer, R. A., Schwartz, S. and Shklar, G. : Oral aspects of mongolism, Part 1. Periodontal disease in mongolism. O. S., o. M. \& o. P., 14: 1, 92, 1961.

[ 8 ] FuKADA, H. and ANDO, A. : A case of periodontosis observed in three year old child. Jap. J. Pedo. $3: 1,71,1963$. (in Japanese)

[9] Kinoshita, I., et al. : Dental observations on dysostosis cleido-cranialis attended by the congenital missing of the bilateral clavicles, J. oral Path., $28: 445-449$, 1961. (in Japanese)

[10] Fukuhara, T. et al. : A report on cleidocranial dystosis with its orthodontic implications, J. J. orth. Soc., $21: 147-153$, 1962. (in Japanese)

[11] OchiAI, Y. : Dental findings of cleidocranial dystosis case, J. oral Path., 28: 445-449, 1961. (in Japanese)

[12] Kishimoto, T. et al. : Dystosis cleido-cranialis case and its dental observations, ShikaiTembo, $24:$ 467, 1966. (in Japanese)

[13] Kurlander, G. J., Lavy, N. W. and Campbell, J. A. : Roentgen differentiation of the occulodentodigital syndrome and the Hallermann-Streiff syndrome in infancy, Radiology, $86: 1,77-86,1966$. 